\title{
Behaviour and Ecology of Male Aye-Ayes (Daubentonia madagascariensis) in the Kianjavato Classified Forest, South-Eastern Madagascar
}

\author{
Doménico Roger Randimbiharinirina ${ }^{a}$ Brigitte M. Raharivololona ${ }^{a}$ \\ Melissa T.R. Hawkins ${ }^{\text {b }}$ Cynthia L. Frasier ${ }^{b}$ Ryan R. Culligan ${ }^{b}$ \\ Timothy M. Sefczek ${ }^{c}$ Richard Randriamampionona ${ }^{d}$ \\ Edward E. Louis Jr. ${ }^{\text {b, d }}$ \\ a Mention Anthropobiologie et Développement Durable, Domaine Sciences et Technologie, \\ Université d'Antananarivo, Antananarivo, Madagascar; ${ }^{b}$ Bill and Berniece Grewcock Center \\ for Conservation and Research, Department of Conservation Genetics, Omaha's Henry \\ Doorly Zoo and Aquarium, Omaha, NE, USA; ' ${ }^{c}$ Department of Anthropology, Ohio State \\ University, Columbus, $\mathrm{OH}$, USA; ${ }^{\mathrm{d}}$ Madagascar Biodiversity Partnership, Manakambahiny, \\ Antananarivo, Madagascar
}

\section{Keywords}

Activity budget $\cdot$ Diet $\cdot$ Home range $\cdot$ Nocturnal strepsirrhines $\cdot$ Primate $\cdot$ Territory

\begin{abstract}
Previous studies found that aye-ayes (Daubentonia madagascariensis) consume a variety of non-invertebrate resources, supporting the hypothesis that aye-ayes are too large-bodied to focus feeding efforts on insects. However, these conclusions were based on introduced populations, with little known about aye-aye behaviour and ecology in its natural habitat. This study investigates activity budgets, diet, and home range/territories of 2 male aye-ayes in the Kianjavato Classified Forest, a disturbed forest in southeastern Madagascar, from October 2013 to October 2014. We used radiotelemetry and focal-animal sampling methods to collect behavioural data. We recorded GPS coordinates of the focal animal every $20 \mathrm{~min}$, calculating the home range size for each individual. Results showed that male aye-ayes spent most of their time feeding and travelling. Their feeding time primarily focussed on larvae and adult insects from various substrates, and to a lesser extent Canarium spp. seeds. Home range sizes of the 2 males varied between individuals, overlapped greatly, and appeared to be related to the location of females. Our findings indicate that aye-aye behaviours are strongly indicative of insect-centric feeding ecology.

(c) 2018 S. Karger AG, Basel
\end{abstract}

\section{KARGER}

(c) 2018 S. Karger AG, Basel

E-Mail karger@karger.com www.karger.com/fpr
Edward E. Louis Jr.

Bill and Berniece Grewcock Center for Conservation and Research, Department of Conservation Genetics Omaha's Henry Doorly Zoo and Aquarium 3701 South 10th Street, Omaha, NE 68107 (USA) E-Mail genetics@omahazoo.com 


\section{Introduction}

Insectivorous primates are typically associated with certain ecological expectations. Insectivores are expected to be small-bodied because invertebrates are not available in large enough quantities to support the necessary energetic demands of primates larger than $500 \mathrm{~g}$ [Kay, 1975; Gaulin, 1979; McGrew, 2001; Raubenheimer and Rothman, 2013; McGrew, 2014]. Additionally, primates relying on insects need to hunt their prey across a large area as invertebrate prey species are rare throughout the environment [Milton and May, 1976; Gaulin, 1979]. Increased territory ultimately results in an increase in foraging and travelling times as the primate hunts for its food [Clutton-Brock and Harvey, 1977]. It is unusual for any species to maintain a body size over $500 \mathrm{~g}$ and overcome the challenges of being predominantly insectivorous.

Aye-ayes were initially described as insectivores despite having an average body size of $2.5 \mathrm{~kg}$, deemed too large to subsist primarily on invertebrates [Petter and Peyriéras, 1970; Kay, 1975; Clutton-Brock and Harvey, 1977; Petter, 1977; Iwano and Iwakawa, 1988]. It has been suggested that the aye-aye's unusual, derived traits, including an elongated, thin, highly flexible middle finger and continuously growing incisors, and unique percussive foraging behaviours allow it to subsist mainly on invertebrates despite its large body size [Cartmill, 1974; Gaulin, 1979; Martin, 1990; Erickson, 1991; Simons, 1995; Erickson et al., 1998].

Other studies contradict the notion that aye-ayes are predominantly insectivorous, instead suggesting a degree of omnivory [Sterling, 1993a, 1994a] or granivory [Iwano and Iwakawa, 1988; Iwano, 1991]. The most significant studies on the behaviour and ecology of the aye-aye have been carried out in artificially established populations introduced in the late 1960s to the island of Nosy Mangabe, in north-eastern Madagascar [Sterling, 1993a; Sterling et al., 1994]. The diet of these animals consisted mainly of seeds from Canarium spp. (Burseraceae), cankerous growths, larvae, and nectar from flowers of Ravenala madagascariensis (Strelitziaceae) [Iwano and Iwakawa, 1988; Sterling, 1993a, 1994a]. Other researchers, focusing on aye-ayes introduced to the Mananara-Nord Biosphere Reserve (11 ha), on the east coast of Madagascar, found that nectar from the flowers of travellers' palm ( $R$. madagascariensis) was the dominant food source during the dry season [Ancrenaz et al., 1994]. Further studies in Mananara-Nord Biosphere Reserve found the major diet composition was coconut flesh and milk, followed by larvae and Terminalia nuts, complemented by a variety of other foods [Andriamasimanana, 1994].

In addition to expanding the dietary repertoire of this species, these introduced populations had large home ranges [Sterling, 1993a, 1994a; Sterling et al., 1994] and high frequencies of foraging and travelling activity [Sterling, 1993a; Andriamasimanana, 1994; Sterling et al., 1994], both of which are expected of primates relying on insects for food. However, large home ranges and relatively high levels of foraging and travelling are also common for omnivores and frugivores [Milton and May, 1976; Clutton-Brock and Harvey, 1977]. Despite previous studies advancing our understanding of aye-aye behaviour and ecology, basic biological data on natural populations are still lacking [Schwitzer et al., 2013].

Our goal was to determine whether behaviours of naturally occurring aye-ayes were similar to previously reported behaviours of introduced populations. We studied the time budget, home range, and feeding time of 2 male aye-ayes for 1 year in 


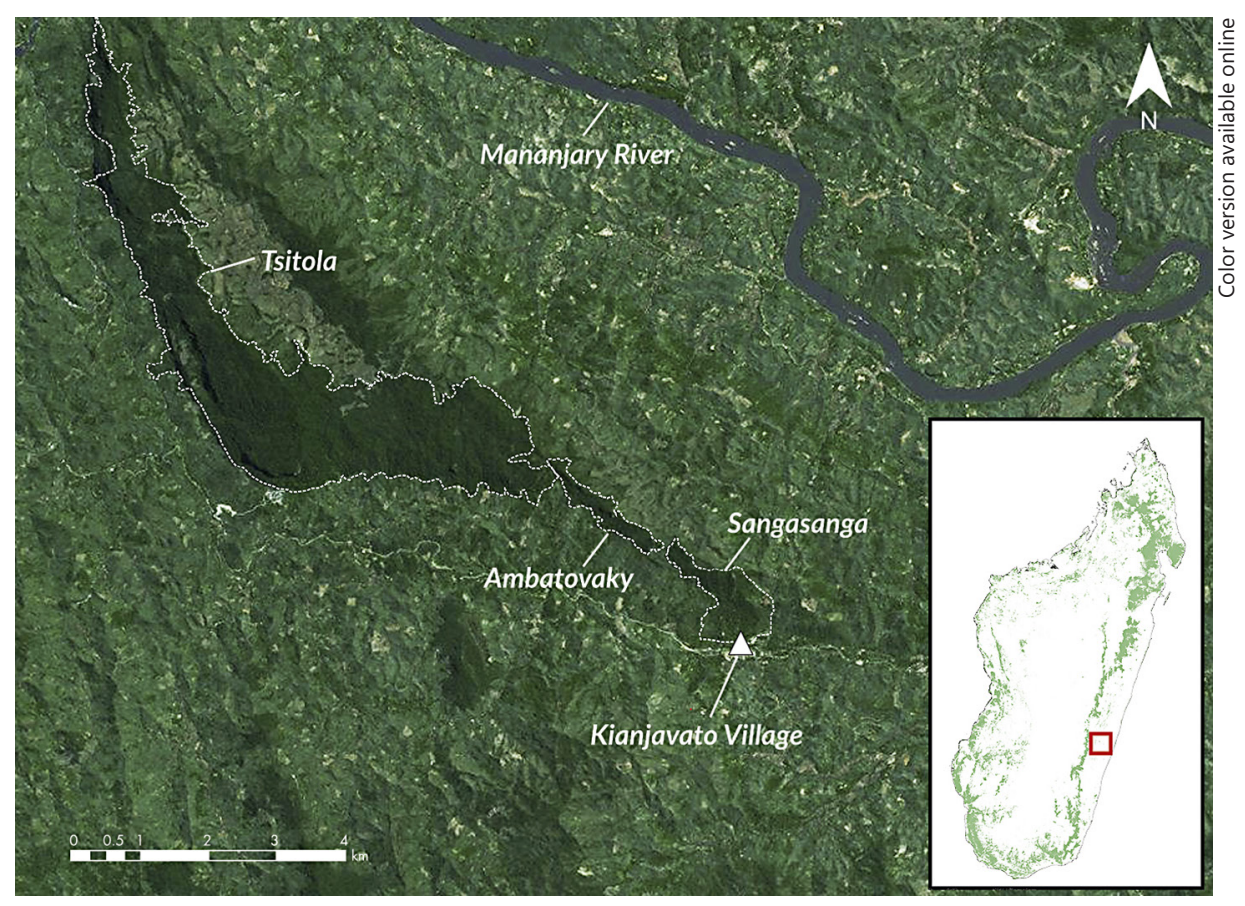

Fig. 1. Map showing the study site of Daubentonia madagascariensis in the Kianjavato Classified Forest, in south-eastern Madagascar, from October 2013 to October 2014 (modified from BD500 FTM 2007 and Holmes et al. [2016]).

Kianjavato Commune, located in south-eastern Madagascar. Our main goal was to determine whether the aye-aye's behaviours were focused on invertebrate or Canarium feeding. We predicted that (1) aye-ayes would spend the majority of their foraging and feeding time extracting and consuming invertebrates, and (2) aye-ayes would spend most of their activity budget feeding and travelling. Lastly, as male home range is often associated with distribution of solitary fertile females, a key resource, we predicted (3) male aye-ayes would maximize their access to this resource by having a range distribution pattern similar to that observed by Sterling [1993b] at Nosy Mangabe, with large overlapping male home ranges and smaller female home ranges.

\section{Methods}

Study Site

We conducted this study in the Kianjavato Classified Forest (KCF hereafter), in south-eastern Madagascar $\left(21^{\circ} 17^{\prime}-21^{\circ} 27^{\prime} \mathrm{S}\right.$ and $47^{\circ} 47^{\prime}-47^{\circ} 58^{\prime} \mathrm{E}$; Fig. 1). This forest is degraded/secondary lowland rain forest, covers an area of 4,875 ha and ranges in elevation from 193 to $291 \mathrm{~m}$ above sea level. The KCF is composed of a conglomeration of agricultural subsistence farming, a coffee plantation (approx. 150 ha) managed by the Centre National pour la Recherche Appliquée sur le Développement Rural or FOFIFA, and a non-protected classified forest (4,725 ha) which is a sec- 
ondary forest interrupted by bamboo [Manjaribe et al., 2013]. Our study area covered the Tsitola, Ambatovaky and Sangasanga forests which are local names for the 3 mountain ranges within the KCF. The natural vegetation surrounding Kianjavato is a low elevation, humid, evergreen forest dominated by Anthostema (Euphorbiaceae) and trees from the family Myristicaceae [Faramalala, 1988]. Due to slash-and-burn agricultural practices, the KCF's landscape is classified as degraded and secondary; it is humid, lowland rainforest [Manjaribe et al., 2013].

\section{Behavioural Data Collection}

Lemurs were captured via a $\mathrm{CO}_{2}$ projection rifle with approximately $10 \mathrm{mg} / \mathrm{kg}$ of Telazol (Fort Dodge Animal Health, Fort Dodge, IA, USA). Once immobilized, we attached VHF radiocollars to them (Advanced Telemetry Systems ${ }^{\odot}$, Isanti, MN, USA, model No.: R410) to allow us to follow the animals via radiotelemetry [Honess and MacDonald, 2011]. All animal handling procedures followed protocols set by the Malagasy regulatory parties for the ethical treatment of non-human primates. Moreover, all interactions with the study subjects abided by Omaha's Henry Doorly Zoo and Aquarium's Institutional Animal Care and Use Committee guidelines (97-001, 12-101).

From October 2013 to October 2014, we monitored 2 male aye-ayes, KIAN13.7 and KIAN13.12, referred henceforth by their nicknames, "Dera" and "Zeppelin", respectively. We followed 1 individual Monday through Thursday each week, and switched between the 2 focal animals weekly. Focal follows were initiated as the animals emerged from their nests and then terminated at 2:00 a.m. at the latest. We collected behavioural data for an average of $5.5 \mathrm{~h}$ per night $(\sigma=0.51)$. We used the focal animal sampling method to collect behavioural data [Altmann, 1974], recording the following activities every $5 \mathrm{~min}$ : feeding, travelling, resting (non-sleeping, stationary), and self-grooming. We used binoculars to observe the animal as it extracted its food. The behavioural category "feeding" includes the extraction time as well as the time spent consuming the food. After the animal had left the food source, we checked the site to determine, to the best of our ability, the food type. Additional behaviours were also collected (such as vocalization and aggression). In addition, we recorded the animal's height in the forest, tree species occupied and diameter at breast height of the said tree, and GPS coordinates (using the WGS 1984 coordisystem) of all feeding sites for each individual, as well as for the localities of the focal animal every $20 \mathrm{~min}$; these are referred to as non-feedGPS locations because they occurred during resting, travelling and other non-feeding events. To determine whether male home ranges were based on reproductive opportunities or resource distribution, we also collected sleep site GPS locations on 1 female aye-aye, KIAN11.6, referred to henceforth by the nickname "Bozy," from October 2013 to October 2014. Every 2 months we took a 2-week break.

\section{Data Analysis and Statistics}

We evaluated activity budgets and time budgets for both males. The activity budget was evaluated by calculating the average percentage of each activity every hour. The time budget was determined by comparing the relative frequency of each activity over the course of the study. We conducted the same analysis to identify the diet composition of the 2 individuals, to determine the proportion of time spent foraging on different food sources, and to investigate the patterns of habitat use by the animals.

We used Excel stat 2015 for our statistical tests. A Shapiro-Wilkes test $(\alpha=0.05)$ showed that data were not normally distributed $(\mathrm{W}=0.145, \mathrm{df}=420, p=0.004)$; therefore, we used nonparametric tests. We used a Mann-Whitney U test (1) to compare behaviours between the 2 individuals to determine whether there were any significant differences in daily activity and (2) to compare the general time budget of the 2 individuals. We conducted a $z$-test in Stat box 6.5 for a comparison of 2 proportions to examine whether the spatial distribution of food sources influenced the distribution of the 2 male aye-ayes. We also performed the $z$-test to compare: (1) the percentage of the feeding GPS locations to the other non-feeding GPS locations recorded for localities within each individual home range and (2) the percentage of feeding GPS locations by each individual inside the overlap of their home ranges compared to the feeding GPS locations outside the overlap of their respective home ranges.

We used the minimum convex polygon and the kernel density estimate (KDE) methods to map and estimate the size of both males' home ranges. The minimum convex polygon method 


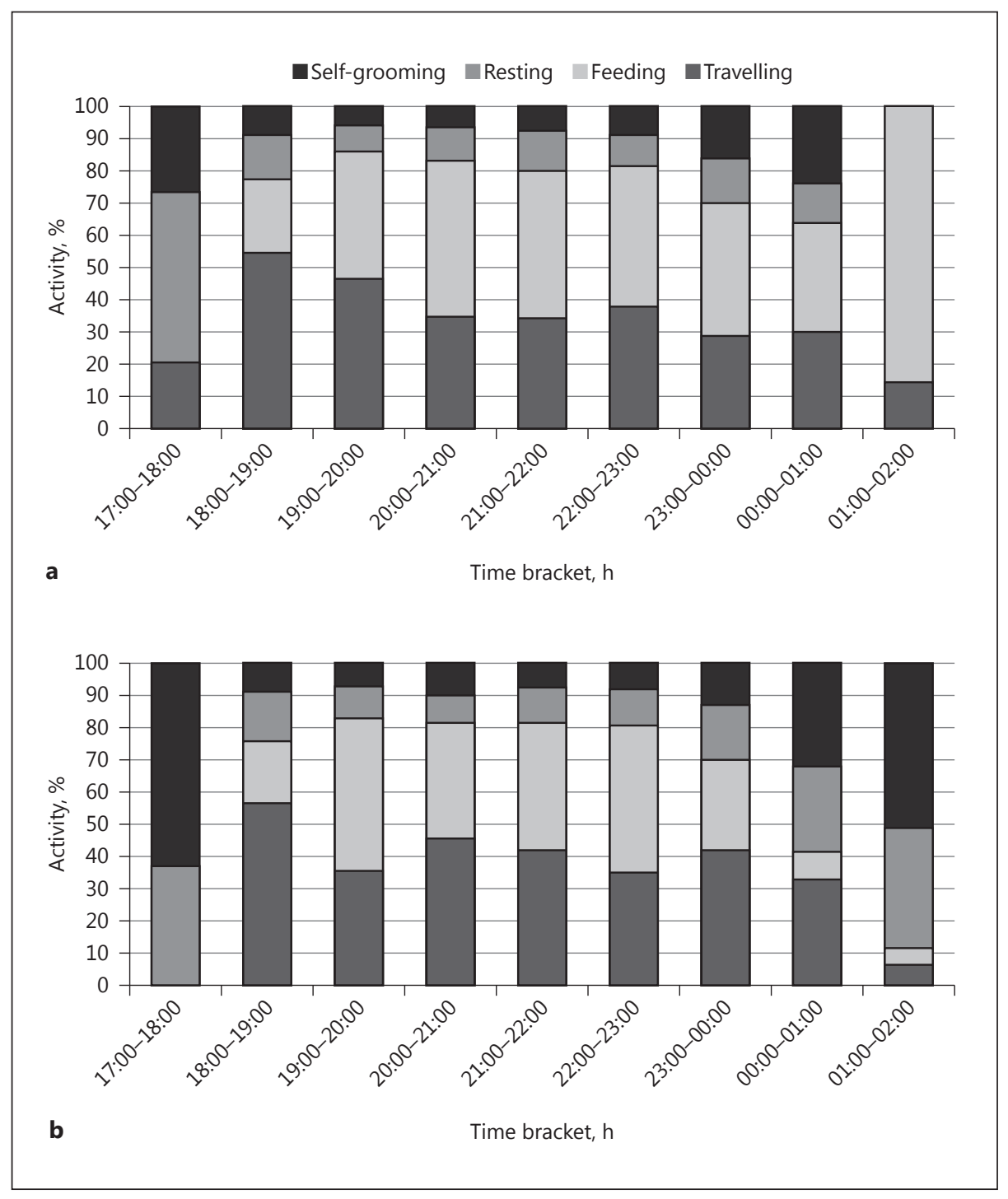

Fig. 2. Daily activity budget for 2 male aye-ayes, Dera (a) and Zeppelin (b), at the Kianjavato Classified Forest from October 2013 to October 2014.

serves to determine the area used by the animal by connecting all the most external locations occupied to form a polygon with convex angles [Mohr, 1947]. Conversely, the KDE method allows us to calculate a magnitude per unit area from point or polyline feature using a kernel function to fit a smoothly tapered surface to each point or polyline. Only the points or portions of a line that fall within the neighbourhood are considered in calculating density; 3 levels (10, 50, and 95\%) should be considered to estimate home range size on KDE [Worton, 1989]. We calculated the area used by each individual in ArcMap v10.4.1. 
Fig. 3. Proportion of different activities for the 2 male ayeayes (Zeppelin and Dera) at the Kianjavato Classified Forest from October 2013 to October 2014.

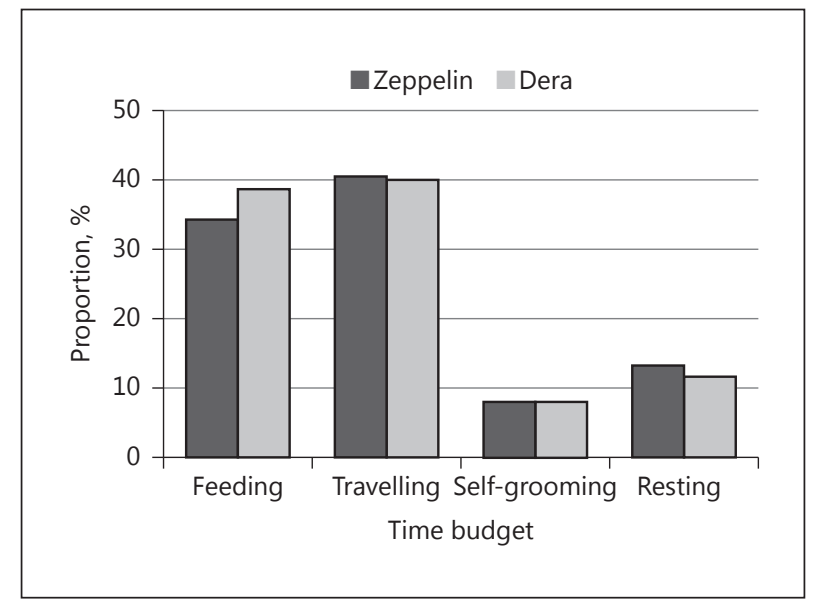

\section{Results}

\section{Activity Budgets}

We followed the 2 male aye-ayes for a total of $373.5 \mathrm{~h}$, with $198 \mathrm{~h}$ (over 44 nights) spent on Dera and $175.5 \mathrm{~h}$ (over 33 nights) spent on Zeppelin. During the dry season, both animals left their nests at $18 \mathrm{~h} \pm 5 \mathrm{~min}$, and during the rainy season, the 2 male aye-ayes left their nests later, at $18 \mathrm{~h} \pm 30 \mathrm{~min}$.

The Mann-Whitney $U$ test found that there was no significant difference between the daily activity of Dera and Zeppelin $(\mathrm{df}=146, \mathrm{U}=38, p=0.63)$. During the first $2 \mathrm{~h}$ after the emergence from the nest, the most frequent behaviours were selfgrooming, then moving, and finally feeding (Fig. 2a, b). From 19:00 h until we left the animals, anywhere between 00:00 and 02:00 a.m., the most frequent behaviours were travelling and feeding, with resting and self-grooming rounding out the rest of the aye-ayes' activities (Fig. 2a, b).

\section{Time Budget}

A Mann-Whitney $U$ test showed that there were no significant differences between the proportion of each type of activity across the entire study of the 2 males $(\mathrm{U}=24, \mathrm{df}=128, p=0.34)$. The 2 animals spent most of their time feeding $(38.53 \%$ for Dera and 34.16\% for Zeppelin) and travelling (39.94\% for Dera and 40.35\% for Zeppelin). Both males were also recorded resting (13.35\% for Zeppelin and 11.52\% for Dera) and self-grooming (8.06\% for Zeppelin and 8.13\% for Dera; Fig. 3). We never observed either grooming or playing between the 2 individuals.

\section{Feeding Time and Food Sources}

The 2 individuals primarily consumed 4 types of food: larvae, seeds of Canarium globosum, Canarium compressum and Canarium lamianum (Burseraceae), together referred to as Canarium spp., nectar from R. madagascariensis (Strelitziaceae), and adult insects. Due to the difficulty in identifying invertebrates, insect prey classification was not specified. 
Fig. 4. Proportion of feeding time per item by the 2 male aye-ayes (Zeppelin and Dera) at the Kianjavato Classified Forest from October 2013 to October 2014.

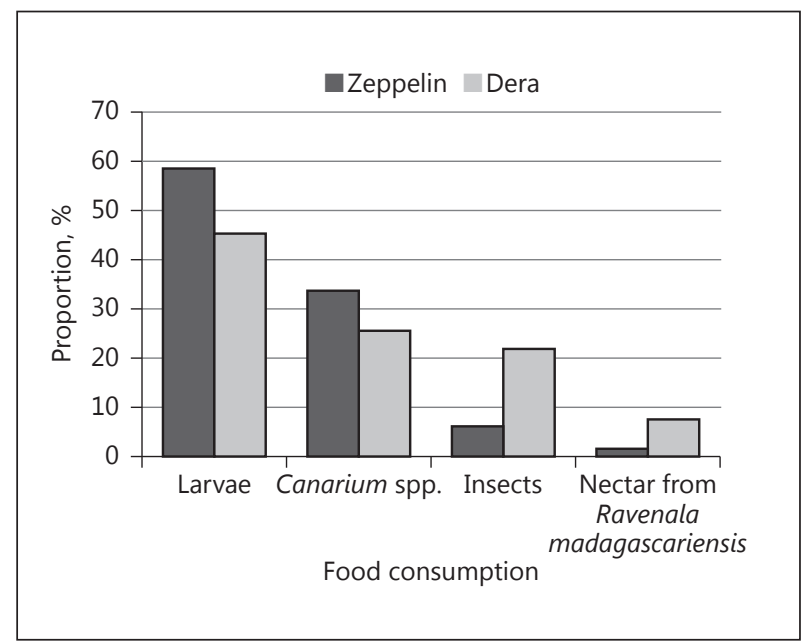

Table 1. Percentage of behaviour records spent on exploration for larvae and insect sources by the 2 male aye-ayes (Zeppelin and Dera) at the Kianjavato Classified Forest from October 2013 to October 2014

\begin{tabular}{lcc}
\hline Food source & Zeppelin & Dera \\
\hline Larvae & & \\
$\quad$ Branch of partially dead wood & 47 & 51 \\
$\quad 53$ & 39 \\
Dead wood & 0 & 10 \\
Trunk of Bambusa vulgaris adult & & 4 \\
Insects & 42 & 96 \\
$\quad$ Ary flower of Ravenala madagascariensis & 58 & \\
\hline
\end{tabular}

Dera spent $45.36 \%$ of his feeding time accessing and consuming larvae, $24.54 \%$ eating Canarium seeds and $21.76 \%$ eating insects. Zeppelin spent $58.7 \%$ of his feeding time consuming larvae, $33.85 \%$ eating Canarium seeds and $6.06 \%$ eating insects. Both males fed on nectar from $R$. madagascariensis for only a small portion of their feeding time (Fig. 4).

Zeppelin extracted larvae from dead wood and from dead branches on live trees an equal amount of the time, while Dera extracted larvae from dead branches on live trees more frequently. Additionally, Dera sought grubs in adult trunks of Bambusa vulgaris (Poaceae) for $10 \%$ of his foraging time (Table 1 ).

In general, the 2 individuals searched for insects on dead flowers of $R$. madagascariensis and on the axil of Dypsis linea (Arecaceae) or "Hovana." While Zeppelin searched for insects slightly more often on the axil of $D$. linea than in the dead flowers of R. madagascariensis, Dera almost exclusively investigated D. linea (Table 1). 
Table 2. Home range size of the 2 male aye-ayes (Dera and Zeppelin) and 1 female (Bozy, nesting site data only) using the kernel density estimation $(\mathrm{KDE})$ and the minimum convex polygon (MCP) methods at the Kianjavato Classified Forest from October 2013 to October 2014

\begin{tabular}{lcccccc}
\hline Aye-aye & \multicolumn{2}{l}{ KDE, ha } & & \multicolumn{2}{l}{ MCP, ha } \\
\cline { 2 - 3 } & $10 \%$ & $50 \%$ & $95 \%$ & & all data & nesting site data \\
\hline Bozy & - & - & - & & 98.20 & 98.2 \\
Dera & 5.98 & 74.36 & 285 & & 973.12 & 870.9 \\
Zeppelin & 35.63 & 148.88 & 265.77 & & 821.55 & 597.5 \\
\hline
\end{tabular}

Table 3. Percentage of behaviour records spent feeding on food items within the male aye-ayes' (Zeppelin and Dera) home range at the Kianjavato Classified Forest from October 2013 to October 2014

\begin{tabular}{lccc}
\hline Food type & $\begin{array}{l}\text { Ambatovaky } \\
\text { forest }\end{array}$ & $\begin{array}{l}\text { Tsitola } \\
\text { forest }\end{array}$ & $\begin{array}{l}\text { Sangasanga } \\
\text { forest }\end{array}$ \\
\hline Zeppelin & & & \\
$\quad$ Larvae & 18.30 & 40.40 & - \\
$\quad$ Canarium spp. & 12.53 & 21.32 & - \\
$\quad$ Insects & 2.00 & 4.06 & - \\
$\quad$ Nectar from Ravenala madagascariensis & 0.40 & 1.00 & - \\
Dera & 10.20 & 15.00 & 20.16 \\
$\quad$ Larvae & 4.15 & 10.00 & 11.40 \\
Canarium spp. & 1.56 & 4.10 & 16.10 \\
$\quad$ Insects & 1.00 & 1.33 & 5.00 \\
$\quad$ Nectar from Ravenala madagascariensis & & & \\
\hline
\end{tabular}

Home range, $K D E$

During our study period, Dera's home range sizes were 5.98 ha (level 10\%), 74.36 ha (level 50\%), and 285 ha (level 95\%). Zeppelin's home range was 35.63 ha (level 10\%), 148.88 ha (level 50\%), and 265.77 ha (level 95\%) (Table 2).

\section{Home Range, Minimum Convex Polygon}

Using all data, Dera's and Zeppelin's home ranges were 973.12 and 821.55 ha, respectively, while the female Bozy occupied only 98.2 ha, based on only sleeping site data (Table 2). The territory of both males overlapped greatly. Zeppelin's home range encompassed the Tsitola and Ambatovaky forests, whereas that of Dera extended from Tsitola forest to the Sangasanga forest (Fig. 5a, b). The size of the overlap of Dera and Zeppelin's ranges was 460.13 ha. Dera's territory almost entirely overlapped Bozy's (covering approx. $95 \mathrm{ha}$ ).

\section{Nesting Site Data}

Using the GPS point for nesting site, Dera's and Zeppelin's home range sizes were 870.9 and 597.5 ha, respectively, while the female Bozy occupied only 98.2 ha (Table 2). The territory of both males still overlapped greatly. The size of the overlap 

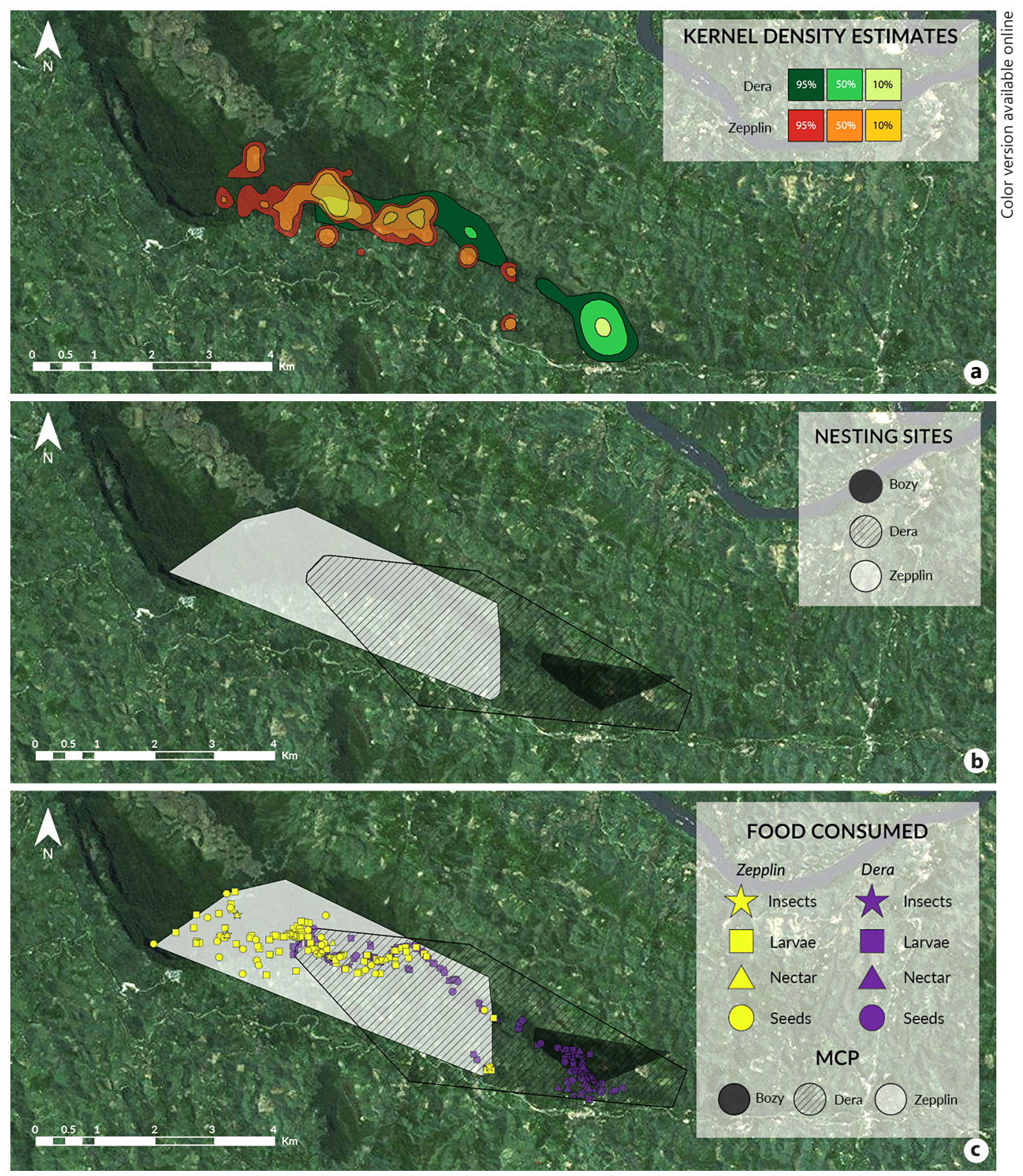

Fig. 5. Map showing home ranges of the 2 male aye-ayes Zeppelin and Dera (a), nesting sites of the female Bozy and the 2 males Zeppelin and Dera (b), and the distribution of food sources exploited by each individual aye-aye (c) within the overlapped territory in the Kianjavato Classified Forest from October 2013 to October 2014. 
Table 4. Percentage of feeding GPS locations and non-feeding GPS locations within home ranges of both male aye-ayes (Zeppelin and Dera) at the Kianjavato Classified Forest from October 2013 to October 2014

\begin{tabular}{lll}
\hline & Zeppelin & Dera \\
\hline Percentage of feeding GPS locations & 48.13 & 59.40 \\
Percentage of non-feeding GPS locations & 51.87 & 40.60 \\
\hline
\end{tabular}

Table 5. Percentage of feeding GPS locations and non-feeding GPS locations inside and outside the overlapped area of both male aye-ayes (Zeppelin and Dera) within their home ranges at the Kianjavato Classified Forest from October 2013 to October 2014

\begin{tabular}{lll}
\hline & Zeppelin & Dera \\
\hline Percentage of feeding GPS locations outside the overlap & 45.45 & 48.45 \\
Percentage of non-feeding GPS locations inside the overlap & 54.55 & 51.55 \\
\hline
\end{tabular}

between Dera and Zeppelin was 370.5 ha, while the size of the overlap between Dera and Bozy was 94.9 ha. Bozy's and Zeppelin's home ranges did not overlap at all. We observed that the home range size based on nesting site data of male aye-ayes is larger than those of the female at the KCF.

\section{Ranging Pattern and Spatial Dispersion of Food Sources}

Zeppelin spent nearly two thirds of his foraging time (67\%) in Tsitola and the rest (33\%) in Ambatovaky. Dera spent about half of his foraging time (52.66\%) in Sangasanga, $30.43 \%$ at Tsitola, and $16.91 \%$ at Ambatovaky. In Tsitola, Zeppelin spent most of his feeding time on larvae and Canarium seeds. While in Sangasanga, Dera mainly focussed feeding time on larvae and insects, followed by Canarium seeds. Nectar consumption always represented the least amount of foraging time by both individuals in all forest patches (all details provided in Table 3 and Fig. 5c).

Within Zeppelin's home range, the percentage of feeding GPS locations was significantly lower than that of other non-feeding GPS locations ( $z$-test, $z=-11.26, p=$ $0.00)$. We observed the same findings within Dera's home range ( $z$-test, $z=-5.90$, $p=0.00$; Table 4). The percentage of feeding GPS locations by each individual inside the overlap did not differ from that of individual feeding locations outside the overlap (in their respective home ranges; for Zeppelin: $z$-test, $z=1.35, p=0.09$; for Dera: $z$-test, $z=0.56, p=0.29$; Table 5).

\section{Discussion}

The large body size of aye-ayes led some to argue they are not predominantly insectivorous [Kay, 1975; Iwano and Iwakawa, 1988; Sterling, 1993a, 1994a]. Our findings suggest that aye-ayes can accommodate an insectivorous lifestyle because of 
their radical morphological adaptations, as mentioned by Gaulin [1979]. Not only did the aye-ayes spend the majority of their time feeding and travelling, covering large home ranges, but the majority of Dera's and Zeppelin's feeding times were spent on invertebrates, with a particular emphasis on larvae. Invertebrates, as well as the ayeayes' second most consumed resource, Canarium seeds, are nutrient rich, and contain large quantities of lipids, protein and carbohydrates [Hladik and Charles-Dominique, 1974; Sailer et al., 1985; Dasilva, 1992; Morland, 1993; Sterling, 1993a, 1994a]. This high-quality diet perhaps allows aye-ayes to maintain their large body size despite Kay's threshold [Kay, 1975]. It is possible that the greater time spent accessing and consuming invertebrates, as opposed to the other available resources, is due to this food item being structurally defended and necessitating a greater amount of time to extract a single larva. However, Canarium seeds are also a structurally defended resource and require aye-ayes to manipulate the food stuff before consumption as well [Iwano and Iwakawa, 1988; Iwano, 1991; Sterling, 1994a]. We cannot definitively identify aye-ayes as insectivorous as we lack consumption rates and resource abundance data to show preferential use of invertebrates compared to other resources. Instead, taken in conjunction with previous research on aye-ayes, our results indicate that this species has a very flexible diet.

\section{Feeding Times and Food Sources}

Our first prediction was that the majority of feeding time would be comprised of invertebrate feeding for aye-ayes in the KCF. Both males spent most of their time accessing and consuming larvae, with Canarium seeds and adult insects rounding out the rest of the feeding time. Compared to aye-ayes in Mananara-Nord Biosphere Reserve and on the island of Nosy Mangabe, the feeding behaviours of the KCF aye-ayes vary considerably. In the Mananara-Nord Biosphere Reserve, coconut flesh and milk, grubs and Terminalia (Combretaceae) seeds made up the bulk of the diet [Andriamasimanana, 1994]. In another part of the Mananara-Nord Biosphere Reserve (degraded forest consisting of grazing land and plantations), nectar from $R$. madagascariensis was the most consumed food item [Ancrenaz et al., 1994]. On Nosy Mangabe, the aye-aye mainly consumed Canarium seeds, cankerous growth, larvae, and nectar from flowers of $R$. madagascariensis [Sterling, 1993a, 1994a].

The differences between our resource feeding time results and those of other studies, when taken in combination, suggest that aye-ayes are more adaptable than we anticipated. The aye-aye is distributed throughout much of Madagascar and survives in various habitat types such as primary rain forests, deciduous forests, secondary forests, plantations, dry scrub forests, coconut groves and mangrove swamps [Ancrenaz et al., 1994; Andriamasimanana, 1994]. Sussman et al. [1985] reported that lemur activity, especially feeding behaviours, depends on the food availability (annually and seasonally) in its habitat. Consequently, aye-aye diets may be flexible as food availability might differ from one habitat type to another. This could explain the dietary variation across the aye-aye's range. It also suggests that the aye-aye's feeding adaptations, while clearly intended for invertebrate foraging, do not limit their ability to consume a variety of other resources.

In the KCF, the aye-aye searched for grubs in dead wood, dead branches in living trees, and in bamboo stalks, but rarely from live wood; we never observed foraging on lianas. During our study period, we heard the crunching sounds from both individuals when they fed on Canarium seeds. We inferred this as evidence of seed con- 
sumption as the locules were empty upon investigation, rather than searching for larvae inside seeds. This is not to say larvae were not present in Canarium seeds at the KCF. Aye-ayes consume larvae and insects from a variety of plant families [see Andriamasimanana, 1994, and Sterling, 1993b, 1994b]; therefore, substrate use for invertebrate feeding may vary across different habitat types. For example, in the Mananara-Nord Biosphere Reserve, the aye-aye extracted larvae from trunks or branches of trees [Andriamasimanana, 1994], whereas, on Nosy Mangabe, the aye-aye foraged for grubs from fallen dead wood, dead branches on a living tree, living trees, dead and living lianas, tree bark, and inside parasitized seeds [Sterling, 1993a, 1994a]. More recently, Sefczek et al. [2017] identified live trees as the most frequently utilized substrate for invertebrate consumption by aye-ayes in the continuous forest tracks of Mantadia National Park and Torotorofotsy Ramsar Site. This again speaks to the ayeaye's adaptability to various environments.

\section{Activity Budget}

Our second prediction was that aye-ayes would exhibit high activity levels, feeding and travelling most often. We discovered up to $80 \%$ of the 2 male aye-ayes' waking time expenditures consisted of travelling and feeding, with only a small amount of active hours spent resting. Compared to other lemur species, D. madagascariensis are very active as Sterling [1993a; Sterling et al., 1994] and Andriamasimanana [1994] also reported. The aye-aye's high levels of activity across their home range could be related to the high nutritional quality of its diet [Hladik and Charles-Dominique, 1974; Dasilva, 1992; Morland, 1993]. Because our observations stopped at 2 a.m., it is possible that the aye-aye's activity levels are skewed toward feeding and travelling. Resting and self-grooming may increase later in the night, after 2 a.m.

Both aye-ayes spent most of their time feeding and travelling between the hours of 19:00 and 1:00 a.m. However, the first hour of activity is different for the 2 males. Dera spent most of the first hour of observation self-grooming, while Zeppelin typically spent the first hour of observation resting (Fig. 2). Additionally, the last hour of observation was typically spent feeding by Dera and resting by Zeppelin (Fig. 2). This may be due to differences in territory, Dera having a more continuous parcel of forest that requires or allows for continued searching for food, while Zeppelin, in a more degraded forest patch, is limited by how much food is available in his home range. Alternatively, it is possible Zeppelin is expending more energy searching for food in his degraded habitat, necessitating a resting period.

\section{Home Ranges}

Our last prediction was that male aye-aye home ranges in the KCF would be closely associated with female distribution. As in Sterling [1993b], male home ranges were large and overlapping, whereas the female's home range was smaller. However, both sexes' home ranges were greater at the KCF (home range was estimated using all GPS data and nesting GPS data). On Nosy Mangabe, male territories ranged from 125 to $215 \mathrm{ha}$, and those of females varied from 30 to 40 ha [Sterling, 1993a, 1994b], whereas the aye-aye territories of the KFC, based solely on sleeping sites, were between 597 and 870 ha for males and approximately 98 ha for the female. The largest calculated home range for all data was 973 ha for Dera and 821 ha for Zeppelin. This difference in home range size is perhaps due to the limited size of Nosy Mangabe, approximately 500 ha [Sterling, 1993a, 1994b]. 
Food distribution did not appear to affect the space use of either male aye-ayes in the KCF. Zeppelin primarily used the Tsitola forest for feeding, while Dera exploited the Sangasanga forest. Dera often came to the surrounding area of Tsitola to forage, whereas Zeppelin never frequented Sangasanga. The main core of the overlap of both males' home ranges was located in the surrounding area of Ambatovaky forest. The percentage of feeding GPS locations for each individual (Dera and Zeppelin) inside their overlapping territories did not differ from the percentage of feeding GPS locations outside their overlapping ranges. It is possible male aye-ayes are not forced to focus on food availability because their main resources, invertebrates and Canarium seed endosperm, are inaccessible for most other animal species. Larvae are contained within a variety of substrates including deadwood, live trees and bamboo, making them cryptic and difficult to access. Similarly, Canarium produce a hard seed coat that most Malagasy animals cannot crack open to use as a food resource [Sterling, 1993a, 1994b]. Thus, the unique adaptations of continuously growing fused canines and incisors and elongated, flexible digits allow the aye-aye to exploit these resources, which other potential competitors lack.

It is apparent that access to females plays an important role in the spatial distribution of male aye-ayes, as previously suggested [Sterling, 1993a; Sterling et al., 1994]. We found that male aye-aye home ranges are larger than those of females, and the male ranges overlapped greatly with each other. Dera's territory overlapped almost entirely with that of the female Bozy. Greater home range sizes in males compared to females are common among non-human primates. For example, subadult and adult male orang-utans (Pongo pygmaeus) in Sumatran swamp forest, SouthEast Asia, had at least a territory of 2,500 ha whereas adult females used a minimum estimated home range of 850 ha [Singleton and van Schaik, 2001]. There are similar findings in male Galago senegalensis, where the distribution of males is strongly influenced by female distribution; female ranging, on the other hand, depends on the distribution of vegetative resources [Bearder and Martin, 1980].

Aye-aye food choices and territories in the KCF differed from those of the introduced population inhabiting the island of Nosy-Mangabe. If habitat permits, an individual aye-aye may prefer to occupy a large home range, which may be more linked to access to either females or food distribution, depending on the sex of the individual. Therefore, results from this study are not only significant to our understanding of aye-aye behaviour and ecology in a natural habitat; but are useful to strengthen the conservation plan of this flagship Malagasy species.

\section{Acknowledgements}

We would like to acknowledge the organizations which financially supported this research: Margot Marsh Biodiversity Foundation, Conservation International, San Diego Zoo, and the Ahmanson Foundation. We thank the Ministry of Environment, Ecology, and Forest of Madagascar for allowing us to conduct this research in the Kianjavato Classified Forest. We also thank the Department of "Anthropobiologie et Développement Durable" of the University of Antananarivo for having approved this research project. Special thanks go to the staffs of the Omaha Henry Doorly Zoo and Aquarium and Madagascar Biodiversity Partnership for their technical and logistical support, and especially to the Madagascar Biodiversity Partnership field assistants: Stéphan Justin Randriambololona, Hubert El-Phanger Fanomezanjanahary, Elysé Fortinand 
Razafindrazefa, Nirina Jean De Dieu Andriamadison, and Nicolas Randrianajafy. Lastly, we thank the anonymous reviewers of this article for their useful comments, and the editors for improving this manuscript.

\section{Disclosure Statement}

There are no conflicts of interest for any author of this manuscript.

\section{References}

Altmann J (1974). Observational study of behaviour. Sampling methods. Behaviour 49: 227-267.

Ancrenaz M, Lackman-Ancrenaz I, Mundy N (1994). Field observations of aye-ayes (Daubentonia madagascariensis) in Madagascar. Folia Primatologica 62: 22-36.

Andriamasimanana M (1994). Ecoethological study of free-ranging aye-ayes (Daubentonia madagascariensis) in Madagascar. Folia Primatologica 62: 37-45.

Bearder SK, Martin RD (1980). The social organization of a nocturnal primate revealed by radio tracking. In A Handbook on Biotelemetry and Radio Tracking (Amlaner CJ, MacDonald DW, eds.), pp 633648. London, Pergamon Press.

Cartmill M (1974). Daubentonia, Dactylopsila, woodpeckers, and klinorhynchy. In Prosimian Biology (Martin RD, Doyle GA, Walker AC, eds.), pp. 655-670. London, Duckworth.

Clutton-Brock TH, Harvey PH (1977). Species differences in feeding and ranging behaviour in primates. In Primate Ecology: Studies of Feeding and Ranging Behaviour in Lemurs, Monkeys and Apes (Clutton-Brock TH, ed.), pp 557-579. New York, Academic Press.

Dasilva GL (1992). The western black and white colobus as a low-energy strategist: activity budgets, energy expenditure and energy intake. Journal of Animal Ecology 61: 79-91.

Erickson CJ (1991). Percussive foraging in the aye-aye (Daubentonia madagascariensis). Animal Behaviour 41: 793-801.

Erickson CJ, Nowicki S, Dollar L, Goehring N (1998). Percussive foraging: stimuli for prey location by aye-ayes (Daubentonia madagascariensis). International Journal of Primatology 19: 111-122.

Faramalala MH (1988). Etude de la végétation de Madagascar à l'aide des données spatiales. $\mathrm{PhD}$ thesis, Université Paul-Sabatier de Toulouse.

Gaulin SJC (1979). A Jarman/Bell model of primate feeding niches. Human Ecology 7: 1-20.

Hladick CM, Charles-Dominique P (1974). The behaviour and ecology of the sportive lemur (Lepilemur mustelinus) in relation to its dietary peculiarities. In Prosimian Biology (Martin RD, Doyle GA, Walker AC, eds.), pp 23-37. London, Duckworth.

Holmes SM, Gordon AD, Louis EE Jr, Johnson SE (2016). Fission-fusion dynamics in black-and-white ruffed lemurs may facilitate both feeding strategies and communal care of infants in a spatially and temporally variable environment. Behavioural Ecology and Sociobiology 70: 1949-1960.

Honess PE, MacDonald DW (2011). Marking and radio-tracking primates. In Field and Laboratory Methods in Primatology, A Practical Guide (Setchell JM, Curtis DJ, eds.), pp 189-205. Cambridge, Cambridge University Press.

Iwano T (1991). An ecological and behavioural study of the aye-aye (Daubentonia madagascariensis). African Study Monographs 12: 19-42.

Iwano T, Iwakawa C (1988). Feeding behaviour of the aye-aye (Daubentonia madagascariensis) on nuts of ramy (Canarium madagascariensis). Folia Primatologica 50: 136-142.

Kay RF (1975). The functional adaptations of primate molar teeth. Journal of Physical Anthropology 43 195-216.

Manjaribe C, Frasier LC, Rakouth B, Louis EE Jr (2013). Ecological restoration and reforestation of fragmented forests in Kianjavato, Madagascar. International Journal of Ecology 13: 1-13.

Martin RD (1990). Primate Origins and Evolution: A Phylogenetic Reconstruction. London, Chapman \& Hall.

McGrew WC (2001). The other faunivory: primate insectivory and early human diet. In Meat-Eating and Human Evolution (Stanford CB, Bunn HT, eds.), pp 160-178. Oxford, Oxford University Press.

McGrew WC (2014). The "other faunivory" revisited: insectivory in human and non-human primates and the evolution of human diet. Journal of Human Evolution 71: 4-11.

Milton K, May ML (1976). Body weight, diet and home range area in primates. Nature 259: 459-462.

Mohr CO (1947). Table of equivalent populations of North American small mammals. The American Midland Naturalist 37: 223-249. 
Morland HS (1993). Reproductive activity of ruffed lemurs (Varecia variegata variegata) in a Madagascar rain forest. American Journal of Physical Anthropology 91: 71-82.

Petter J-J (1977). The aye-aye. In Primate Conservation (Prince Rainier III of Monaco, Bourne GH, eds.), pp 37-57. New York, Academic Press.

Petter J-J, Peyriéras A (1970). Nouvelle contribution à l'étude d'un lémurien malgache: l'aye-aye. Mammalia 34: 167-193.

Raubenheimer D, Rothman JM (2013). Nutritional ecology of entomophagy in humans and other primates. Annual Review of Entomology 58: 141-160.

Sailer LD, Gaulin SJC, Boster JS, Kurland JA (1985). Measuring the relationship between dietary quality and body size in primates. Primates 26: 14-27.

Schwitzer C, Mittermeier RA, Davies N, Johnson SE, Ratsimbazafy HJ, Razafindramanana J, Louis EE Jr, Rajaobelina S (eds.) (2013). Lemurs of Madagascar. A Strategy for their Conservation 2013-2016. Bristol, IUCN SSC Primate Specialist Group.

Sefczek TM, Randimbiharinirina D, Raharivololona BM, Rabekianja JD, Louis EE Jr (2017). Comparing the use of live trees and deadwood for larval foraging by aye-ayes (Daubentonia madagascariensis) at Kianjavato and Torotorofotsy, Madagascar. Primates 58: 535-546.

Simons EL (1995). History, anatomy, subfossil record and management of Daubentonia madagascariensis. In Creatures of the Dark: The Nocturnal Prosimians (Alterman L, Doyle GA, Izard MK, eds.), pp 133-140. New York, Plenum Press.

Singleton I, van Schaik CP (2001). Orangutan home range size and its determinants in a Sumatran swamp forest. International Journal of Primatology 22: 877-911.

Sterling EJ (1993a). Behavioural Ecology of the Aye-Aye (Daubentonia madagascariensis) on Nosy Mangabe, Madagascar. PhD thesis, Yale University, New Haven.

Sterling EJ (1993b). Patterns of range use and social organization in aye-ayes (Daubentonia madagascariensis) on Nosy Mangabe. In Lemur Social Systems and Their Ecological Basis (Kappeler PM, Ganzhorn JU, eds.), pp 1-10. New York, Plenum Press.

Sterling EJ (1994a). Aye-ayes: specialists on structurally defended resources. Folia Primatologica 62: 142 154.

Sterling EJ (1994b). Taxonomy and distribution of Daubentonia madagascariensis, a historical perspective. Folia Primatologica 62: 8-13.

Sterling EJ, Dierenfeld ES, Ashbourne CJ, Feistner ATC (1994). Dietary intake, food composition and nutrient intake in wild and captive populations of Daubentonia madagascariensis. Folia Primatologica 62: 115-124.

Sussman RW, Richard AF, Ravelojaona G (1985). Madagascar: current projects and problems in conservation. Primate Conservation 5: 53-58.

Worton BJ (1989). Kernel methods for estimating the utilization distribution in home range studies. Ecology 70: 164-168. 